\title{
The Online Pandemic in Design Courses: Design Higher Education in Digital Isolation
}

\author{
Katja Fleischmann \\ Griffith University, Queensland College of Art, Australia \\ k.fleischmann@griffith.edu.au
}

\begin{abstract}
Design education is at the crossroads of re-defining itself in the midst of the COVID pandemic. Design educators are now part of a global movement to work in isolation through web-based communication and collaboration tools, which are also at the heart of a decentralised workforce encountered in the design profession. With its social isolation requirements, many universities have closed down their physical classes and lecture halls and have required educators to abruptly transition their courses to an online delivery. Although this transition is not universally endorsed, it has forced the hand of design educators who have been reluctant to jump into the online world with both feet. As the literature reveals, many blended learning solutions have been trialled but few design educators have made online teaching and learning an ongoing building block of their design courses. This chapter examines the outcomes of this foundational shift from face-to-face design studio teaching to online by surveying design students and educators at an Australian university. The results are surprisingly optimistic but there are challenges that need to be addressed by institutions to make this transition work in the post-pandemic world. The central research question is: Will design educators who are now working in an online environment go back to the physical classroom and lecture halls once the pandemic restrictions ease? Or is online design education now a central part of the design curriculum?
\end{abstract}

Keywords: design studio education, online design education, COVID-19 pandemic, remote teaching, technology-enhanced design education 


\section{Introduction - Design's Studio Education}

Design studio education is derived from the 'atelier' method from the 'Ecole Des Beaux Arts' model (1819-1914) which was also adapted by the influential Bauhaus School (1919-1932). In design studio education, students approach learning from a traditional masterapprenticeship relationship with the master (educator) sharing their knowledge and skills with the apprentice (student), hence the educator is guiding students in their creative development (Crowther, 2013; Lee, 2006; STP, 2009).

Students who want to enter the design profession most often engage in project-based learning as part of their studies (Ellmers, 2006; Poggenpohl, 2012; Shreeve et al., 2008). In these projects, which often simulate professional practice (Fleischmann \& Daniel, 2010; Shreeve, 2011), students are given a design problem that they would encounter as professional designers. In these authentic scenarios, students are guided by the educator to solve the problem by applying a design process used in practice (Fleischmann \& Daniel, 2010; Öztürk \& Türkkan, 2006).

Design teaching and learning is highly interactive. Learning is structured by an ongoing dialogue between students, educators and tutors who are often design practitioners (Danvers, 2003; Fleischmann, 2012; Shreeve, 2011). Technical support staff in computer labs and other hands-on labs (e.g. laser cutting, 3-D printing facilities) are also involved in this dialogue guiding students in their creative explorations. A culmination of this dialogue is often the 'crit' or critique, that occurs frequently in formal and informal ways from educators, tutors, peers or visiting professionals (Blythman et al., 2007; Fleischmann, 2012; 2016). In these critiques, students pin their work-in-progress to the wall or present their projects more formally to receive feedback from the educator and/or peers, and at times from design professionals. This ongoing process of receiving feedback and guidance is intended to lead to improvement (learning) through a cycle of action and reflection (Schön, 1987). This distinguishing characteristic of design studio education differentiates it from many other programs of study in a university.

The dialogical approach to learning and teaching design is adapted in most design schools throughout the world and across varying design disciplines such as interior design, visual communication design, product design, architecture and urban design (Crowther, 2013). During feedback sessions, peer feedback, peer assessment and peer learning are also essential elements in the reflective learning cycle by exposing students to multiple perspectives (Fleischmann, 2016; Shreeve et al., 2010). Although peer interaction allows for multiple conversations to be held at one time, the way design is taught and learned puts restrictions on the numbers of students in one room during a tutorial, a critique or workshop. Reasonable class sizes for activities in design studio education are considered to be between 12 and 20 depending on the kind of activity, although economic pressures in universities have seen these class sizes increase (Marshalsey \& Sclater, 2018; Shreeve, 2011; STP, 2009).

Design studio education has a high social dimension, and is regarded by many researchers such as Shreeve (2011) as a learning environment and social space. The challenge for design educators has been to translate this studio pedagogy into an online environment, particularly on such short notice.

\section{The Webcam Versus Lecture Hall - Emerging Research During the Pandemic}

Given design's traditional reliance on studio-based teaching and learning, there has been a natural resistance by design educators to transition their studio to an online environment (Fleischmann, 2015; Mohammed, 2017; Saghafi et al., 2012).

But that resistance has collapsed under the rapid spread of the COVID-19 pandemic, which has forced design educators to cope with a world without walls. While studio-based pedagogy 
with its highly social aspect has long been the foundation in design education, the theoretical underpinnings of online delivery are just beginning to emerge and are largely based on the efficacy of collaboration software in approximating the studio setting.

This transition to a digital design education has prompted one educator to develop a pedagogical theory for online design education. Dreamson (2020) has focused on what he calls "metaconnective pedagogy" which "is focused on learners' connective experiences in the digitally networked environment, and its holistic, systematic approaches to connectivity" (p. 484). Dreamson (2020) asserts that the atelier approach to design education is an anachronism in a digitally networked world. The author argues that networked knowledge is "tremendously faster than the transition from masters to apprentices... This means that design studios could no longer be the mainstream route for career development" (p. 495).

Dreamson (2020) appears to be in the minority of design educators who are actively trialling different approaches to online instruction given the pressures of putting their courses online. The pandemic has raised important pedagogical issues about how to teach design online. Those issues revolve around the efficacy of online teaching and learning in the realm of collaboration, critiques, and hands-on design practices. The pandemic is forcing the rethinking and re-assessment of studio practice in light of the digital tools needed to approximate studio-based learning and the problems that arise with this kind of approach from educator and student perspectives.

There is no question that design educators are employing new digital tools that allow them to transition design studio practice to an online environment without being totally convinced the online paradigm could be effective. COVID-19 has accelerated the process of trialling and testing those tools. One of the issues examined in this process was encountered at Zayed University in the United Arab Emirates where Ahmad, Sosa and Musfy (2020) were looking at alternative ways to present interior design projects in a physical gallery. As an alternative, 23 graduating interior design students presented their final projects in a virtual gallery augmented by e-folio websites. The authors singled out 'cultural barriers' where students felt uncomfortable using live web streaming services to present their projects.

At the Faculty of Architecture and Design at Özyeğin University in Istanbul, Yorgancioğlu (2020) cited student unease with facing an online camera and expressing their opinions, particularly during online design crits which suffered lower student participation rates. Problems with synchronous design crits also included tutors having to allocate more time to deliver feedback, and no way of knowing if students were actually hearing peer feedback when using digital collaboration platforms such as Zoom, Microsoft Teams and Skype.

Lee et al. (2020) examined the use of a widely utilised collaboration software, Slack, in a postgraduate Master program focusing on service and interaction design. Slack uses instant messaging and chat features that promote higher speeds of interaction as opposed to email and online learning management platforms which do not invite rapid collaboration and do not have robust collaborative functionality.

In surveying their 12 graduate students, the authors found "Slack was perceived as a particularly user-friendly tool when the substance of collaboration is the exchange of different media. Furthermore, its integrated messaging and update functionality allowed students to perform project management activities more easily" (Lee et al., 2020, p. 8)

Central to the adoption of online design courses is professional development opportunities for faculty who are unfamiliar with implementing online courses. Although not specifically relating to design disciplines "Teaching, Technology, and Teacher Education During the COVID-19 Pandemic: Stories from the Field" (AACE, 2020), present a number of strategies to help faculty cope with this rapid transition. Ervin-Kassab (2020) proposed creating an online "sandbox" for educators not familiar with online delivery tools to test software in the creation of courses.

Williams (2020) suggested creating an interdisciplinary support network for educators looking for resources to transition to online. In a similar strategy Greene (2020) proposes 
creating on-demand professional development resources for educators unfamiliar with online teaching for her institute's education faculty.

It should be noted that some design programs, particularly in Europe, have returned to faceto-face classrooms while others, like in Australia, are still taught online at this time (September, 2020). The emerging research clearly demonstrates that design educators are adapting as fast as possible using digital tools, particularly for online communication and collaboration. While some design educators appear to have overcome their scepticism about aspects of online design teaching during the pandemic, there are misgivings about the limitations of this online world and how it will work without sacrificing the benefits of a studio-based design education:

"...the limits of the digital tools we use will begin to determine the limits of teaching and learning experiences both for the tutors and the students. This will weaken the potentials of the intuitive, spontaneous or experimental dimensions of design learning that are embedded in design education" (Yorgancioğlu, 2020, p. 34).

\section{Online Design Courses Pre-Pandemic}

Before the COVID-19 pandemic forced a re-casting of studio-based design education, design educators-although in the minority-had already begun experimenting with teaching design in blended and online environments. Blended learning describes a mix of activities that require physical presence of students and educator in a learning space with parts of the class being offered online. Students have to some extent control over time, pace and place of their learning. Online education exists in either a synchronous or asynchronous mode. The course content is available and delivered fully in an online learning space. Asynchronous refers to learning with no real-time interaction with educators and gives a student the most control when, where and at what pace to study. Synchronous online design education, although delivered fully online, has an aspect where students and educators are meeting at a specific time online in a virtual space (e.g. to participate in a tutorial, a lecture or for receiving feedback). The synchronous online mode is the delivery model most institutions used during the COVID-19 pandemic-it is often also referred to as remote teaching.

Various advantages to delivering some aspects of design courses online have been identified particularly in the areas of critiquing and timely feedback. In previous studies that explored the efficacy of blended and online design education (Fleischmann, 2018a; Fleischmann, 2019; Fleischmann, 2020) the author reviewed existing research in strictly online design learning and teaching environments; various advantages were identified by researchers in adopting online tools:

- students become more self-reliant when it comes to developing their own expertise if an expert is not available in the studio for immediate feedback (Lotz, Jones \& Holden, 2015),

- immediate response and feedback are possible (McNamara, 2015),

- asking students to critique online leads to higher level of participation in collaboration (McIntyre, 2007), and

- unlimited exposure to peer progress is possible (Güler, 2015).

As technology advances, so do options for design educators to introduce online elements to their courses, particularly web-based collaboration and classroom critiques. Student participation and a willingness to take responsibility for their learning are crucial to making online (and also blended) learning and teaching approaches work (Fleischmann, 2020; Wanner \& Palmer, 2016).

It is noteworthy that pre-pandemic, most examples of strictly online design education were introduced to unite remote cohorts of students (often located in different countries and/or institutions), educators and professionals through the use of internet technology in collaborative design projects. The author found in her own trials (Fleischmann, 2019) that 
strictly online design courses are particularly suitable for those students who need to manage demands of family, work and social commitments while studying.

The research (Fleischmann, 2019) also showed that not all design courses are equally suited to be taught as fully online courses. Introductory design courses with digital product outcomes such as graphic design and interactive media can work well while others that require handson workshops and the creation of physical objects are less likely to be successful in a fully online environment. However, these courses are often well suited to be offered in a blended learning/teaching mode where the hands-on workshops would be offered in a face-to-face setting-a finding also confirmed by Saghafi et al. (2012). Fleischmann (2019) asserts that "there is no question that in certain contexts, online design education is possible and does produce positive results from student and teacher perspectives" (p. 14).

Nevertheless, a blended approach to design teaching and learning with some aspects of courses to be delivered online emerges as a preferred middle ground between fully face-toface and fully online education (Fleischmann, 2018a; 2020). The "flipped classroom" in which students watch the lecture content via online videos before attending face-to-face tutorials or studio time emerged as one model of preference - despite also presenting challenges (e.g. Baytiyeh, 2017; Fleischmann, 2020; Wanner \& Palmer, 2016; Yick et al., 2019).

The COVID-19 pandemic has essentially accelerated this often trial-and-error process as design institutions make the transition to internet-delivered courses without the luxury of a phased-in approach that would otherwise be possible. This chapter is essentially sampling how this online transition is working so far in an Australian university where design has been taught and learned primarily in a studio-based environment; only one educator had introduced an online trial with a selected group of design students last year and concluded, "online could only ever supplement face-to-face teaching and not replace it completely in design education"; in fact, the majority of educators held dim views about teaching online before they began their rapid transition to web-based delivery. The well-worn idiom, 'He who hesitates is lost', defined the urgency of educators having to restructure their classes to make them work online as best as possible despite their scepticism and lack of experience.

\section{Research Methods: The Abrupt Switch from Studio-based Education to Remote Online Teaching and Learning}

This study explores what happened at the design programs at the Queensland College of Art (QCA), Griffith University in Australia, in the midst of the COVID-19 pandemic. Courses up until the pandemic were usually taught in a studio-based environment. That means, lectures are held in large lecture theatres (50-150 students). The lectures are automatically recorded through the university recording system for students who cannot attend-however it is expected that the majority of students attend lectures face-to-face. The tutorials (usually 2 hours) are held in a studio environment with pin up walls, in computer labs or workshops (e.g. 3D-printing lab, wood workshop).

Tutorial groups usually have up to 20 enrolled students. Depending on the design course, there can be up to ten tutorials per course held across two campus locations. A course describes a 12-week unit of study. A course might be called a subject in other universities. Full-time design students usually enrol in three to four courses per trimester.

In Trimester 1 design students experienced four weeks of the traditional face-to-face design studio education. In week 5 (March 2020) a COVID-19 lockdown was introduced in Australia; universities closed and students, tutors, educators, technical staff and administrators had to work from home. As of this writing, this lockdown is still being enforced at the author's institution (September, 2020). When the lockdown commenced, design courses needed to be immediately taught remotely (online) for the remaining eight weeks of the trimester. The student and educator participants in this research are studying/teaching in the Bachelor and Master of Design. 
This research is framed by a pragmatic approach (Creswell, 2003; Johnson \& Onwuegbuzie, 2004; Punch, 2009) which enabled the researcher to select methods that suit the real-world practice nature of the situation. In this case, the research was conducted via online surveys using the software, Survey Monkey. The survey was intended as a real time snapshot of the issues facing both educators and students coping with the isolation demanded by the university because of physical distancing requirements brought by the pandemic. The issues being explored included student and educator attitudes toward online design courses, the types of technological changes employed to deliver those courses, and the results of those changes, both positive and negative.

A total of 52 design students and ten educators responded to the survey which was designed to collect quantitative data and rich qualitative data. Questions were designed to deliver base line information about changes and technologies used in the online design classroom and both cohorts were given opportunities to provide lengthier explanations about their survey responses. A qualitative analysis of those comments was conducted. The qualitative feedback was analysed inductively with themes quickly emerging (Saldana, 2009). To allow for a weighting (more/less important) the comments within one theme were quantified in terms of the number of times they were referred to by students and educators.

\section{Findings: Thumbs Up from Students for Convenience and Fast Feedback; Thumbs Down on Motivation and Social Isolation}

Students who completed the survey were studying in the Bachelor of Design (83\%) and the Master of Design (17\%) and represented a wide cross section of design disciplines.

The majority of the design students $(65 \%)$ were studying communication and graphic design, $10 \%$ were studying product design and $8 \%$ were studying interior design. The remaining students represented other design disciplines, such as industrial design and interactive media. Some students were studying double majors/degrees such as design and business.

Before the pandemic, only $19 \%$ of design students had studied online before. Amongst the educators, the majority had never taught using the internet as their major interface with students. Of the courses that were studied by students, the majority $63 \%$ were both theory and practice-based while $26 \%$ of students studied practice-based courses.

The changes introduced are described by a student: "all face-to-face teaching has gone online. The lectures were pre-recorded and tutorials were held in Collaborate Ultra at a specific time." Some educators did not pre-record their lecture but gave them "live" in the virtual classroom (Collaborate Ultra) during scheduled lecture time.

Students mentioned that assessments for creating physical objects were adjusted as they could not access the workshops on campus. Some educators "divided [their cohorts] into small collaborate groups, and [students] were collaborating more through shared documents... which helped to have a better collection of information"-as one student reported.

When asked to evaluate their overall learning experience in the virtual classroom, $53 \%$ of design students "liked it", while $38 \%$ were undecided but liked certain aspects of the online delivery. Only $8 \%$ of design students stated that they did not like the online delivery of courses and one international student commented that online design courses did not deliver value for money. Overall, students agreed that the transition from face-to-face teaching to online teaching was handled extremely well by educators.

A major pillar of design education is the dialogic process in the studio tutorial - the give-andtake of action, feedback and reflection which according to student feedback, was enhanced by the online delivery. When asked to explain which aspects of online design courses they liked the highest number of students (36) commented that they were able to get more feedback from tutors and also peers about their work, reflected in the following survey explanations: 
- "Sometimes I get even more feedback from the teachers than I did before. I guess when you are in a class full of people it is sometimes easy to just stay quiet and not speak up."

- "I think that the teachers have been actually been giving us more feedback, ...we are also pushed more to provide feedback to other people in class."

The online feedback process is accomplished with collaborative software, microphones, webcams and email, which actually made some students feel better connected with classmates and tutors:

- "I felt closer to my tutors as we get more one on one time and feedback from tutors as well as peers."

The increased feedback also benefitted some students, who found that they could progress their work better: "My classes were more feedback focused and that allowed me to progress further in the assessment."

Students also remarked that studying online required of them to participate more actively in the tutorials: "I liked being made to communicate with other classmates in the online classes" while two students commented that they felt more comfortable making online presentations. Twenty-three students cited convenience and the fact that they saved time and money not having to commute to campus for face-to-face classes. Two students commented that the extra time savings allowed them to work more on assessments. The casual nature of working from home was also singled out by 14 students as a benefit of participating in design courses online. Two students commented they could do their classwork wearing pyjamas and another said they could go barefoot. "It felt a lot more relaxed," commented one student. From a content perspective, reviewing tutorial recordings was also cited as a benefit of working online: "Everything in the classroom is recorded so if I don't understand something I can watch it over and over again."

Aside from convenience and more engagement with tutors and peers, there were multiple challenges identified by students to adapting to a strictly online delivery, which included:

- Social isolation and motivation

- Privacy concerns

- Difficulty collaborating in group projects

- Technical issues with the internet

- Time budgeting (students have to be more disciplined in organising their day)

Lack of motivation (cited 23 times) and coping with social isolation (cited 36 times) topped the list of problems students expressed while studying design online. The issues involving lack of motivation and social isolation were many.

Time management and distractions working from home diminished motivation to attend a virtual class and/or watch pre-recorded lectures online; while social isolation issues included students missing the give-and-take of working with their peers in face-to-face collaboration. It is clear from the following remarks, that not all students felt part of the online design dialog:

\section{Diminished motivation}

- "I had trouble getting motivated and not being lazy with keeping up with my workload."

- "It was hard to stay motivated because I had too much time on my hands... and it was difficult to create a work ethic from home."

\section{Well-being affected}

- "I am much more accustomed to online learning, but at times I still struggled with motivation and felt extremely stressed."

- "Adjusting to a new routine, that took a long time and a big toll on my mental health."

\section{Distracted at home}

- "I had constant distractions at home (my dogs, TV, other household chores sitting in the back of my mind that should be done)." 
- "I felt more easily distracted when the communication is not face-to-face."

The lack of motivation was also a reason for some students to not watch online lectures: "I didn't watch many lectures, however I used to attend all physical lectures-again lacking motivation." In general some students commented: "I stopped watching online, I simply read the lecture slides."

\section{Social Isolation}

\section{Lack of body language/facial expressions}

- "You don't get to see facial expressions to see if others understand/not understand."

- "It is harder to deliver ideas, as it is easier to show sketches, make body position, and emotionally relate to your team members."

\section{Lack of team/group/peer interaction}

- "Having the online sessions meant that we missed out on group activities and interaction with the lecturer."

- "The class was not as interactive as it was in person. The only aspect I have experienced change is that there is a lot less interaction between my peers, and not having their feedback on work, like you would have in person."

\section{Missing out on peer sharing and exchange}

- "Lack of creativity as I live by myself and have nobody to bounce ideas off."

- "I miss team-based learning and bouncing ideas off other students and also looking at other people's work (also with assignment it is good to know where others are up to so you can keep track of your own work)."

These social deficits from working in digital isolation were best summed up in this student comment: "I couldn't socialise, collaborate and communicate with friends in person."

From a technical standpoint, many students cited poor internet connectivity, bad sound quality and webcam issues in collaborative internet sessions.

These issues were best summed up in this student comment: "Everything depends on the network quality; sometimes students couldn't join the online class or be late". The technical complaints were cited 26 times by students at both the onset of their online courses and after they were well into their trimester courses. The technical challenges were wide ranging and included:

- Connectivity (Internet dropping out or being slow)

- Difficulty uploading assignments

- Learning new software

- Using a microphone for the first time

- Not having a good webcam

- Lack of support for helping with technical issues such as software

Relating to technical issues was the aspect of online sharing and personal privacy. One student complained about discomfort about fellow students seeing their home spaces and appearing online when their webcams were on. "I felt very awkward talking to a screen and seeing myself on the screen. It felt like an invasion of my privacy as everyone could see into my bedroom which is my private space."

When inquiring about the quality of work produced in the online learning and teaching situation compared to the traditional face-to-face studio, $40 \%$ of students said they produced better work when learning face-to-face, $22 \%$ of design students agreed that their produced better outcomes when learning online because they had more time and could focus better, and $30 \%$ said their online work was about the same quality. 
When asked how the current experience could be enhanced, the following suggestions to improve the online delivery of courses were made:

- Real time lectures that are streamed live with more information on the slides rather than just images that would be explained in the lecture;

- Show examples of concepts and discuss; make videos a little interactive and interesting;

- Make sure the viewing platform allows for the video to be a reasonable size, without having to be full screen and offer video speed adjustment settings.

\section{Educators Moving Toward Digital Platforms}

Ten design educators responded to the survey, five of them having more than ten years of experience teaching design. Six out of ten said they are not sure yet if student work has improved in an online delivery and the same number said they had never had any experience teaching an online course pre-pandemic.

Some of the educators were sceptical about being able to teach design courses online, best summed up in this comment: "I perceived it as a limited experience in which communication and engagement would not be as efficient, key ideas would easily be missed and students would not receive a quality learning experience." Others saw the value of online teaching as part of a blended approach, characterising internet delivery as "complementary to the physical studio" or as a "supplement" to face-to-face teaching.

Most educators (83\%) were required to suddenly move their courses to an online delivery system on very short notice and comments sometimes reflected a discomfort with having to make such a rapid transition to online delivery. Criticisms centered on the digital tools available. The delivery of courses relied heavily on the Learning Management System Blackboard to transmit critical components of the course materials.

For some educators that platform was "clumsy" and made their administrative work more difficult, also reflected in six student criticisms of what one called "disorganised classes" with confusing navigation to find schedules or the location of their virtual class. One educator commented: "The main difficulties were around technical issues such as internet speed, audio and visual issues. At times the transitions between tasks such as beginning and ending breakout sessions were 'clunky' or 'awkward'." Another educator described the online experience as "limiting, frustrating, and impersonal. The platform makes sharing student work (design drawings) difficult and clunky and everything seems to take longer."

One educator, however, was impressed by the versatility of the virtual classroom technologyCollaborate Ultra (Blackboard):

"Being able to view design work up close and being able to draw on and mark up the designs for everyone to see was very helpful. Breakout sessions (after being set up) also seemed to work better. Students seemed to be more talkative and less shy. I also found feedback from students to their peers increased during assessment presentations. Tasks such as brainstorming yielded far stronger results than in face-to-face settings. Above all though - the best aspect of online was the ease and ability to 'share screens' on my personal desktop. This enabled me to give quick software demonstrations of techniques and processes which students said they greatly appreciated. It also enabled quick spontaneous sharing of relevant work from my archives that related feedback or tasks."

Collaborate Ultra was one of a number of learning platforms employed for feedback, collaborative group work and digital communication; the top six platforms are ranked below in order of use:

- Collaborate Ultra (virtual classroom in Blackboard) (Presentations, real-time critiquing and demonstrations of studio techniques, collaborative work)

- Blackboard Learning Management System (Administrative tasks, such as posting assignments, video lectures, resources and announcements)

- Microsoft Teams (Presentations, group meetings and peer and educator feedback)

- Email (One-on-one communication between educator and students) 
- Zoom (Presentations, peer and educator feedback)

- Google Docs (Shared documentation and assignments)

Similar to some students, two educators struggled with the anonymity of the virtual environment. As one educator describes: "Communication has been difficult. Many students don't turn their video on so I feel like I'm teaching a brick wall." Another educator characterised the lack of participation in online courses as students "hiding from learning duties," coupled with less accountability. Others struggled with motivation to teach in an online setting. "I don't feel as motivated to teach online as I do face-to-face. I find it difficult to 'read the classroom' which I rely on to shift the content to student needs." One educator confirmed that view with a succinct reason they prefer face-to-face. "Now that I've experienced teaching online, it's confirmed my preference for teaching face-to-face. I've also found it to be more convenient for many people, including myself. But just because something is convenient, doesn't make it effective or meaningful."

Another educator cited better student engagement for those students motivated enough to attend the online session: "The positives are that the students who do turn up online are mostly very engaged and many don't mind the online format at all". Another praised the feedback loops engendered by online courses: "Assessment and feedback works extremely well online."

When asked to comment on design classes that do not fit into the online paradigm, eight out of ten educators cited the limitations of online classes to teach skills that require tactile sense and actual hands-on practices. The workshop skills mentioned included product design where students would need to make moulds, and skills needed to made physical 3D models and 3D printing.

Many educators and students commented in the survey that smaller class sizes helped them feel more engaged. Of the ten educators, eight think a class size of 15-20 students would work well in a synchronous online environment. One educator would start with a class of 24 and then split them in groups of 12 per tutorial, which supports the idea of a smaller class as well. Similarly, $71 \%$ of design students stated a class size of 20 students or less would be most engagaing for them.

All but one educator agreed that their workload had increased when delivering online courses; one educator stated that it was about the same as delivering the classes in a face-to-face environment.

Suggestions from educators on how to improve the online student experience included smaller class sizes, better digital tools such as more designer focused mark-up software, more modularized classes with pre-produced worksheets for break-out sessions, and implementing micro-credentialing and short course structures. One educator mentioned preparing weekly self-taught modules for students.

\section{Conclusion: Is the Design Studio now a Digital Reality?}

Design education is at the crossroads of re-defining itself in the midst of the COVID pandemic. Design educators are now part of a global movement to work in isolation through web-based communication and collaboration tools, which are also at the heart of a decentralised workforce encountered in the design profession. Perhaps this transition from studio to a virtual classroom could not have come at a better time, when web-based technology is making online communication and collaboration a necessity and also possible.

The purpose of this survey was to take a closer look at how the COVID pandemic is impacting design programs at an Australian university, where educators were forced to move their courses to a fully online delivery due to nationwide social distancing requirements that closed down the classrooms. Central to this research was discovering what worked and what didn't for students and their educators, most of whom had little experience teaching and learning 
online before the pandemic. The pandemic forced the rapid transition to digital delivery and provided a unique opportunity to survey current student/educator attitudes and compare the findings with pre-pandemic research into online versus blended approaches (Fleischmann, $2018 \mathrm{a} ; 2018 \mathrm{~b} ; 2019 ; 2020)$. There was a marked congruence in findings pre- and postpandemic.

As explored in the introduction, design studio education has certain unique properties that make a full transition to teaching and learning fully online problematic, particularly in tactile design disciplines that still work best in a studio or workshop setting. Confirming existing findings (Fleischmann, 2019; Saghafi et al., 2012), courses like product design or courses where print work is required, suffered through the pandemic because they require students to learn skills that are difficult to digitally model.

There are social problems associated with a strictly online design classroom. Lack of motivation, isolation, and stress were identified by a large number of students as by-products of doing courses outside a bricks-and-mortar context.

Sharing ideas with peers and bouncing ideas of each other are key features of design studio education. This social component was missed by students in a strictly online classroom. Design by its very nature is a collaborative enterprise and an online delivery makes the human aspect of that equation more difficult to deliver.

Digital communication and collaboration tools that were already trialled pre-pandemic have allowed the collaboration process of a studio-based pedagogy to proceed remotely; however, design educators steeped in the tradition of a studio-based pedagogy have found the transition has highlighted many challenges as well as benefits.

The results of the survey indicate that educator workload has dramatically increased with delivering online design courses-a findings also mentioned by Yorgancioğlu (2020), but many educators have adapted well to teaching online.

Most educator criticism centers on the limitations of university-based technologies such as learning management system software and lack of hands-on instruction in tactile design disciplines. Students who participated in the survey favoured the convenience of online learning, although some admitted that they did not watch recorded lectures or show up to their virtual classes; however, students generally embraced online tutorials with faster digital feedback mechanisms-confirming findings of earlier conducted studies (Fleischmann, 2019; 2020).

Both educators and students cited problems with some digital tools, although both cohorts viewed these problems from different perspectives. Student concerns centred on personal computer issues such as balky internet connectivity, using webcams and microphones for the first time, and unfamiliarity with some of the software being newly employed in class for collaboration such as Miro, Microsoft Teams and Collaborate Ultra.

The results of the survey and qualitative analysis indicate that students are generally comfortable with online delivery of their courses and were highly satisfied and appreciative of how smooth educators made the transition for students from one week of face-to-face teaching on campus to the next week of having classes online. Behaviourally, students who were generally shy in face-to-face situations found a digital comfort online. For these students there was more ease when they made their presentations and felt they could participate in the class more. Similiarly, Saghafi et al. (2012) discovered that web-based learning can contribute "to a sense of "security" (p. 16) in students. That ususally shyer students participated more, is an observation also highlighted by one educator in this study. However, other educators commented that students seemed less engaged and one commented that students were "hiding" in the virtual classroom.

Conversely, many of the students also said they found feedback from educators was faster; they received more feedback and they felt tutors were more engaged. This is a very positive outcome given that learning in design studio education is based on action and reflection which is triggered by the dialogical approach of giving and receiving feedback. 
When asked to expand their views on the challenges of working online, the distractions of working from home weren't the only problems. A small number of students also felt less engaged during group collaborative sessions and were missing facial expressions and body language-a challenge also mentioned by educators in this and in an earlier study (Fleischmann, 2019). Many students cited lack of motivation as the biggest problem with transitioning to online courses-a concern raised by other design students who voiced that face-to-face interaction helps them learn (Fleischmann, 2018a); some students need the physical class space to focus, get organised and for social interaction.

It is clear from the survey results that both educators and students have embraced at least some important aspects of the online design classroom, particularly in the timeliness of collaborative feedback and the convenience of studying from home.

But both cohorts are still not unanimously embracing a fully online design classroom experience. Both students and educators have highlighted technical, social, and curricula shortcomings that are still being ironed out.

For example, although cited for convenience, there was less student engagement in asynchronous learning such as watching online video lectures. Some students lacked the motivation to watch the lectures while others found them hard to understand, despite being able to watch them repeatedly. The asynchronous learning dimension of online design courses warrants further research into comprehension of theoretical concepts and better methods for interactivity to measure that comprehension.

Most educators and students in this study had no prior experience with teaching or learning fully online. From survey comments, educators who had to rapidly transition from teaching face-to-face to online reflect both misgivings and support of its application in design courses: "I didn't realise how easily students would take it on"; "Now that I have experienced teaching online, it is confirmed my preference for teaching face-to-face"; "I was aware that change was necessary and was ready for the challenge...I hope that the experience has woken a few people up." It is clear from this small sample of educators that the transition to online design courses mirrors a range of experiences and educator confidence in the technology used to deliver the courses. At the very least, educators with little or no online teaching experiences prior the pandemic are now open to the idea of implementing some aspects of design teaching online.

There is a clear willingness by both educators and students to engage with enhanced, webbased approaches in the future-an observation also advanced by Yorgancioğlu (2020). However, there is still a reluctance to teach and study design courses fully online, confirming the author's earlier findings at a different institution (Fleischmann, 2018a; 2020). In the current study, none of the design educators would teach design fully online after the pandemic, however $16 \%$ of design students are open to studying a course fully online ( $8 \%$ asynchronous and $8 \%$ synchronous) based on what they had experienced in the virtual classroom. Sixtypercent of design educators and $35 \%$ of design students would see a blended learning and teaching approach as an opportunity to move forward after the pandemic (most likely in a flipped classroom approach). Thirty-seven percent of the students say they still prefer faceto-face design classes.

In the short term, a move to a fully online model cannot be anticipated at the author's institution nor on a global scale. This study reports on experiences during the pandemic from one Australian university with similar results emerging in a presently internationally conducted survey with design educators from New Zealand, Europe and the US. The author will present those findings in the near future.

This study also confirmed important observations regarding class sizes in technologyenhanced design education. Smaller class sizes have always been an important factor to make the highly interactive face-to-face design studios work. It is notable that despite a common belief one can cater for larger student numbers in an online environment-a view partially 
driven by universities that are under increasing economic pressure caused by the pandemic this is not the case for design education. 'Smaller is better' is also true for learning and teaching design in synchronous online environments. Both design educators and students agree that the success of synchronous online tutorials which had real-time interaction, feedback sessions and group interaction, relies on smaller class sizes between 15-20 students. The often cited "flipped classroom" where lectures are accessible online for students to watch before attending the tutorial (online or face-to-face) might be seen as a new 'go-to' model. Existing research has highlighted both advantages and challenges (Baytiyeh, 2017; Coyne et al., 2017; Fleischmann, 2020; Foldnes, 2016; Koo et al., 2016; Wanner \& Palmer, 2016) and clearly highlights that students need to be highly self-reliant and self-motivated to make a flipped classroom work (Fleischmann, 2020; Wanner \& Palmer, 2016) particularly for first year students (Yick et al., 2019).

The results of this study also show a need for educational institutions to invest time and money into professional development for their design educators to make a transition to more technology-enhanced design education, blended or online, as smooth as possible.

That means giving their design educators the time and training they need to offer the students a rich, interactive experience online. Further research and experimentation with technology in design curriculum development will help refine the role of web-based delivery of design courses whether it is in a blended setting or completely online. Clearly there is more work that needs to be done to test and verify the place of online technology in design educationmost certainly more research will emerge as a result of the pandemic that will contribute to shaping future design education. This study has pointed out that the answer to the question: Is the Design Studio dead?-is a qualified "No, not yet."

\section{References}

AACE. (2020). Teaching, Technology, and Teacher Education During the COVID-19 Pandemic: Stories from the Field. Available from https://www.learntechlib.org/p/216903/.

Ahmad, L., Sosa, M., \& Musfy, K. (2020). Interior Design Teaching Methodology During the Global COVID-19 Pandemic. Interiority, 3(2), 163-184. doi:10.7454/in.v3i2.100

Baytiyeh, H. (2017). The flipped classroom model: when technology enhances professional skills. The International Journal of Information and Learning Technology, 34(1), 51-62. doi:10.1108/IJILT-07-2016-0025

Blythman, M.; S. Orr \& B. Blair (2007). Critiquing the Crit. University of the Arts London.

Coyne, R. D., Lee, J., \& Petrova, D. (2017). Re-visiting the flipped classroom in a design context. Journal of Learning Design, 10(2), 1-13. doi.org/10.5204/jld.v10i2.281

Creswell, J. W. (2003). Research design: Qualitative, quantitative, and mixed methods approaches (2nd ed.). Thousand Oaks: Sage.

Crowther, P. (2013). Understanding the signature pedagogy of the design studio and the opportunities for its technological enhancement. Journal of Learning Design, 6(3), 18-28.

Danvers, J. (2003). Towards a Radical Pedagogy: Provisional Notes on Learning and Teaching in Art \& Design. International Journal of Art \& Design Education, Vol. 22, No. 1, pp. 47-57.

Dreamson, N. (2020). Online Design Education: Meta-Connective Pedagogy. iJADE, 39(3), 483-497. doi:10.1111/jade.12314

Ellmers, G. (2006). Reflection and Graphic Design Pedagogy: Developing a Reflective Framework to Enhance Learning in a Graphic Design Tertiary Environment. Paper 
presented at the ACUADS 2006 conference, Monash University, School of Art, Victorian College of the Arts, Melbourne.

Ervin-Kassab, L. (2020). Playing with Faculty: Creating a Learning Management "Sandbox". In R. E. Ferdig, E. Baumgartner, R. Hartshorne, R. Kaplan-Rakowski, \& C. Mouza (Eds.), Teaching, Technology, and Teacher Education During the COVID-19 Pandemic: Stories from the Field (pp. 17-22).

Fleischmann, K., \& Daniel, R. (2010). Enhancing employability through the use of real-life scenarios in digital media design education. In E. Errington (Ed.), Preparing Graduates for the Professions Using Scenario-based Learning (pp. 85-96). Mt Gravatt: PostPress.

Fleischmann, K. (2012). Industry-driven design education: How much should market/industry dictate pedagogy? In G. Muratovski (Ed.), agIdeas Research: Design for Business (Vol. 1, pp. 76-95). Melbourne: agIdeas Press.

Fleischmann, K. (2015). Democratisation Of Design And Design Learning - How Do We Educate The Next-Generation Designer. International Journal of Arts \& Sciences, 8(6), 101-108. Available from http://www.universitypublications.net/ijas/0806/pdf/B5R188.pdf

Fleischmann, K. (2016). Peer Assessment: A Learning Opportunity for Students in the Creative Arts. In C. Nygaard, Branch, John and Bartholomew, Paul (Ed.), Assessing Learning in Higher Education (pp. 45-58). Oxford: Libri Publishing.

Fleischmann, K. (2018a). Online design education: Searching for a middle ground. Arts and Humanities in Higher Education, 19(1), 36-57.

Fleischmann, K. (2018b). Hype or Help? Technology-enhanced Learning in the Design Classroom: An Experiment in Online Collaboration. International Journal of Arts \& Sciences, 11(1), 331-342. Available from http://universitypublications.net/ijas/1101/pdf/M8K144.pdf

Fleischmann, K. (2019). From studio practice to online design education: Can we teach design online? | De l'enseignement pratique en studio à l'enseignement en ligne : peut-on enseigner le design en ligne ? Canadian Journal of Learning and Technology, 41(1), 119. doi:10.21432/cjlt27849

Fleischmann, K. (2020). Hands-on versus virtual: Reshaping the design classroom with blended learning. Arts and Humanities in Higher Education, 1-26. doi:10.1177/1474022220906393

Foldnes, N. (2016). The flipped classroom and cooperative learning: Evidence from a randomised experiment. Active Learning in Higher Education, 17(1), 39-49.

Greene, K. (2020). À La Carte and On-Demand: Professional Development for Educator Preparation. In R. E. Ferdig, E. Baumgartner, R. Hartshorne, R. Kaplan-Rakowski, \& C. Mouza (Eds.), Teaching, Technology, and Teacher Education During the COVID-19 Pandemic: Stories from the Field (pp. 33-42).

Güler, K. (2015). Social media-based learning in the design studio: A comparative study. Computers \& Education, 87, 192-203.

Johnson, R. B., \& Onwuegbuzie, A. J. (2004). Mixed Methods Research: A Research Paradigm Whose Time Has Come. Educational Researcher, 33(7), 14-26.

Koo, C. L., Demps, E. L., Farris, C., Bowman, J. D., Panahi, L., \& Boyle, P. (2016). Instructional design and assessment: Impact of Flipped Classroom Design on Student 
Performance and Perceptions in a Pharmacotherapy Course. American Journal of Pharmaceutical Education, 80(2), 1-10.

Lee, N. (2006). Design as a learning cycle: A conversational experience. Studies in Learning, Evaluation Innovation and Development, Vol. 3, No. 2, pp. 12-22

Lee, T., Pham, K., Crosby, A., \& Peterson, F. (2020). Digital collaboration in design education: how online collaborative software changes the practices and places of learning. Pedagogy, Culture \& Society, 1-16. doi:10.1080/14681366.2020.1714700

Lotz, N., Jones, D., \& Holden, G. (2015). Social engagement in online design pedagogies. Paper presented at the 3rd International Conference for Design Education Researchers, Aalto University.

Marshalsey, L., \& Sclater, M. (2018). Critical perspectives of technology-enhanced learning in relation to specialist Communication Design studio education within the UK and Australia. Research in Comparative \& International Education, 13(1), 92-116. doi: $10.1177 / 1745499918761706$

McIntyre, S. (2007). Evaluating Online Assessment Practice in Art and Design. UNSW Compendium of Good Practice in Learning and Teaching, 1-32.

McNamara, P. (2015). The influence of MOOCs to enhance graphic design education. Art, Design \& Communication in Higher Education, 14(1), 57-69.

Mohammed, M. F. M. (2017). Blended E-learning in the architectural design studio: an experimental model. International Journal of Parallel, Emergent and Distributed Systems, 32(sup1), 73-81. doi:10.1080/17445760.2017.1390103

Öztürk, M. N., \& Türkkan, E. E. (2006). The Design Studio as Teaching/Learning Medium A Process-Based Approach. International Journal of Art and Design Education, 25(1), 96-104.

Poggenpohl, S. H. (2012). Envisioning a Future Design Education: An Introduction. Visible Language, 46(1/2), 8-19. Available from http://visiblelanguagejournal.com/web/current_issue

Punch, K. (2009). Introduction to research methods in education. London: Sage.

Saghafi, M. R., Franz, J., \& Crowther, P. (2012). Perception of Physical versus virtual design studio education. International Journal of Architectural Research: ArchNet-IJAR, 6(1), 6-22.

Saldana, J. (2009). The coding manual for qualitative researchers. London: Sage.

Schön, D. (1987). Educating the Reflective Practitioner, Jossey-Bass, San Francisco.

Shreeve, A. (2011, 18-19 May 2011). The Way We Were? Signature pedagogies under threat. Paper presented at the Researching Design Education: 1st International Symposium for Design Education Researchers; CUMULUS ASSOCIATION// DRS, Paris, France

Shreeve, A., Sims, E., \& Trowler, P. (2010). 'A kind of exchange': learning from art and design teaching. Higher Education Research \& Development, 29(2), 125-138.

Shreeve, A., Wareing, S., \& Drew, L. (2008). Key Aspects of Teaching and Learning in the Visual Arts In H. Fry, S. Ketteridge, \& S. Marshall (Eds.), A Handbook for Learning and Teaching in Higher Education: Enhancing Academic Practice (pp. 345-362). New York and London: Routlege.

STP. (2009). Curriculum Development in Studio Teaching: Volume One: STP Final Report. Studio Teaching Project. Available from https://ltr.edu.au/deeplink.aspx?TN=resources\&RF=Full\%20Display\&AC=QBE_QUER 
$\mathrm{Y} \& \mathrm{XC}=\% 2 \mathrm{Fdbtwwpd} \% 2 \mathrm{Fexec} \% 2 \mathrm{Fdbtwpub} . \mathrm{dll} \& \mathrm{QY}=$ find $\% 20$ systemid $\% 20 \mathrm{ct} \% 20365$ 297

Wanner, T., \& Palmer, E. (2016). From Flipped to Flopped to Flexible classrooms in Higher Education? - Critical Reflections from Australia. Paper presented at the ASCIKITEShaping the future of tertiary education, Adelaide. Australia.

Williams, S. (2020). Virtual Professional Development Design for Inservice Teachers During the Pandemic. In R. E. Ferdig, E. Baumgartner, R. Hartshorne, R. Kaplan-Rakowski, \& C. Mouza (Eds.), Teaching, Technology, and Teacher Education During the COVID-19 Pandemic: Stories from the Field (pp. 549-556).

Yick, K.-1., Yip, J., Sau-chuen Au, Lai, Y.-y., \& Yu, A. (2019). Effectiveness of blended learning in the first year of fashion education. International Journal of Fashion Design, Technology and Educational Technology \& Society, 12(2), 178-188. doi:10.1080/17543266.2018.1546910

Yorgancioğlu, D. (2020). Critical Reflections on the Surface, Pedagogical and Epistemological Features of the Design Studio under the "New Normal" Conditions. Journal of Design Studio, 2(1).

\section{Proud Pen}

(C) 2020 The Author(s). Licensee Proud Pen Limited. This chapter is distributed under the terms of the Creative Commons Attribution License (https://creativecommons.org/licenses/by/4.0/), which permits unrestricted use, distribution, and reproduction in any medium, provided the original work is properly cited.

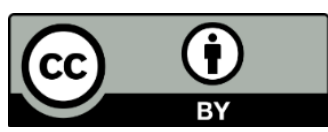

